\title{
EDUCAÇÃO AMBIENTAL NA EDUCAÇÃO ESCOLAR E A RESPONSABILIDADE SOCIAL: DESAFIOS E POSSIBILIDADES NAS QUESTÕES AMBIENTAIS
}

Genesio Mario da Rosa ${ }^{1}$

Fabiana Regina da Silva ${ }^{2}$

Kauane Andressa Flach ${ }^{3}$

Resumo: O presente texto tem por objetivo inter-relacionar os temas Responsabilidade Social e Educação Ambiental na educação escolar, através de uma discussão das relações envoltas entre sociedade e o meio ambiente, fundamentada em pesquisa bibliográfica e legislação, de abordagem qualitativa. Como resultados, infere-se que os conceitos que envolvem a Educação Ambiental são aplicáveis quando compreendidos na complexidade, contextualizados e desmistificados do ponto de vista ambiental, social e econômico, e são necessários para a efetiva compreensão e aplicação da Responsabilidade Social. Ainda que a orientação legal imponha limites e responsabilidades ao uso dos recursos naturais, esse deve ser também consciente e estar intimamente ligado ao ensinoaprendizagem escolar.

Palavras-chave: Educação Ambiental; Responsabilidade Social; Ação Antrópica.

Abstract: This text aims to interrelate the themes Social Responsibility and Environmental Education in school education, through a discussion of the relationships between society and the environment, based on empirical, bibliographic and legislation research, with a qualitative approach. As a result, it is inferred that the concepts that involve Environmental Education are applicable when understood in complexity, contextualized and demystified from the environmental, social and economic point of view, and are necessary for the effective understanding and application of Social Responsibility. Although the legal guidance imposes limits and responsibilities on the use of natural resources, it must also be conscious and be closely linked to school teaching and learning.

Keywords: Environmental Education; Social Responsibility; Anthropogenic Action.

\footnotetext{
1Universidade Federal de Santa Maria. E-mail: genesiomario@yahoo.com.br, Link para o Lattes: http://lattes.cnpq.br/6868821306663236

2Universidade Federal de Santa Maria. E-mail: fabianareginadasilva@yahoo.com.br,

Link para o Lattes: http://lattes.cnpq.br/6154300779166221

3Universidade Federal de Santa Maria. E-mail: kaauane_flaach@hotmail.com,

Link para o Lattes: http://lattes.cnpq.br/4670534796764262
} 


\section{Introdução}

As relações - meio ambiente e os recursos naturais, seu uso, conservação e regeneração, mesmo não estando sempre atrelada ao conhecimento científico, paradigmas e conceitos, entre eles 0 de sustentabilidade, historicamente estiveram presentes nas percepções humanas, suas formas de vida e em suas construções culturais. Tão logo o homem percebeu que precisava plantar para manter segura a alimentação e viabilizar a continuidade e fortalecimento da reprodução das primeiras comunidades primitivas, tivemos a invenção da agricultura. No entanto, com o passar dos séculos, o desenvolvimento urbano, demográfico, científico, cultural, industrial, a expansão do capitalismo e a percepção da demasiada e desregrada exploração dos recursos naturais, faz com que essas questões passem a ganhar importância nos espaços científicos, acadêmicos e políticos mundiais, principalmente representados em formações coletivas como órgãos internacionais. Novas condições de produção e consumo colocam no cenário a necessidade de reflexões atentas sobre a ação antrópica, questões como a sustentabilidade, a educação para com o ambiente e a natureza e, a Responsabilidade Social.

A sustentabilidade, conceito este que passou a ser delineado na Conferência das Nações Unidas sobre o Meio Ambiente Humano (United Nations Conference on the Human Environment - UNCHE), realizada na cidade de Estocolmo, na Suécia, em junho de 1972, incumbe uma definição ligada ao ato de defender e melhorar o ambiente humano para as atuais e futuras gerações. Estas pontuações também estão presentes no Relatório de Brundtland, publicado em 1987, ao ressaltar que o uso sustentável dos recursos naturais deve "suprir as necessidades da geração presente sem afetar a possibilidade das gerações futuras de suprir as suas" (CMMAD, 1991). Nessa perspectiva, evidencia-se a necessidade de um olhar mais amplo para seu real entendimento e aplicação. Assim, a apropriação do conceito se faz presente nos "Objetivos de Desenvolvimento Sustentável (ODS) proposto pelas Nações Unidas em 2015, que fornecem diretrizes para avançar em direção a sociedades sustentáveis e equitativas e tem implicações de longo prazo" (CHAKRAVORTI, 2017).

A sociedade industrializada e urbanizada e suas implicações, entre elas, a necessidade de pensar mais atentamente sobre as relações sociais, dimensões e interferências no meio natural, nos remetem as contribuições de grandes pensadores da sociedade moderna, demarcada por estas inúmeras transformações que nos forneceram paradigmas e modos de vida, interfaces da nossa relação com a sociedade e a natureza.

Ao circundar a análise e reflexão aqui proposta à luz da Educação Ambiental, segue-se a concepção de Holliday (2006) de que entender esse processo (pensamento), produzir um novo conhecimento, a partir de um primeiro nível de conceitualização, possibilita sua compreensão e induz a uma transcendência. Nessa ótica, tendo como pano de fundo nossa relação com a sociedade e o meio ambiente ao partir da sociedade moderna, é possível 
revisitar o que pensadores do século XIX e início do XX, como Durkheim, Karl Marx e Max Weber, definiram para as relações entre os indivíduos e as organizações sociais e econômicas, pautando quase massivamente 0 pensamento, até boa parte do século XX. Porém, em outro viés, já considerando as emergências contemporâneas e as questões aqui tratadas, é importante articular-se também à visão complexa da realidade social e ambiental de Edgar Morin, em uma pretensa superação epistemológica da dicotomia da modernidade e dos discursos e orientações mais cartesianas.

Situadas no período acima mencionado, as produções de Emile Durkheim emergiam em seus estudos sociológicos, sua perspectiva de fato social. O pensador considera o todo preexistente, exterior, em que o homem é inserido ao nascer, explicando questões conceituais como a coerção social exercida sobre este, e a coesão social em situação de solidariedade mecânica e orgânica, assim, demonstra a compreensão da relação homem e sociedade como fundamental para clarificar os aspectos sociais e a realidade em que se vive. Por outro lado, Karl Marx considera que a sociedade só pode ser explicada a partir do modo com que os indivíduos se organizam para produzir os bens necessários, ou seja, suas relações voltadas para as bases materiais da existência, na interferência e transformação da natureza, e em si próprios através do trabalho e da produção cultural. Porém, os detentores dos meios de produção são responsáveis pela produção alienada ao todo, pela falta de compreensão e consciência deste todo, o que desresponsabiliza de certa forma, o trabalhador dos danos à natureza. No entanto, um passo adiante de Durkhein, Max Weber considera importante compreender que as ações sociais resultam e são influenciadas pelas ações dos sujeitos componentes da sociedade, em uma relação de interdependência em relações sociais, sentidos de ação e motivações compartilhadas, leis causais.

Ao fazer uma sintética análise das teorias apresentadas pelos pensadores citados no parágrafo acima, é possível, em perspectiva crítica, perceber as influências que estas construções somadas a outras, tiveram por boa parte do século XIX e XX, na forma de se pensar questões como a educação e a relação humana com o meio ambiente e, em alguma medida, é possível relacioná-las em um intuito de pensar as evidentes carências em termos de pensar a Responsabilidade Social e a Educação Ambiental.

De todo modo, neste ponto situa-se um dos primeiros passos para o entendimento de que as relações sociais com o meio são inevitáveis para a manutenção e evolução de nossa espécie nesse planeta. Nessa perspectiva, a escola como instituição social precisa contemplar a construção de uma proposta de educação integral, capaz de conscientizar os educandos de tais imbricações. Em um passo adiante, é preciso compreender a complexidade da relação com o meio ambiente, que o cuidado com a nossa casa e mãe natureza deve ser tal, que seu uso não esgote os recursos naturais e que os resíduos dos processos de produção não sejam fatores de contaminação irreversível no meio, seja pelo descarte incorreto ou por danos acidentais de seu acondicionamento, se inviável for o seu reuso.

revista brasileira educação ambiental 
Neste propósito, a reflexão acadêmica e científica é sempre necessária, entendendo que é preciso partir da compreensão da incompletude e da incerteza, da construção e reconstrução, mas também, de que o contexto social e ambiental é historicamente construído e não está à parte do campo epistemológico. Desse modo, refletir sobre questões como a Educação Ambiental como um dos propósitos da Responsabilidade Social, requer contemplar um continuum de pensamentos e formas conscientes de conserválo para as gerações futuras.

Cada ser é em sua magnitude, parte integrante desse planeta onde está ativamente relacionando-se com outros e mantendo as relações organizacionais com um todo complexo e não determinista e compartimentado, acionando Morin (2007). Por isso, as ações antrópicas estão diretamente relacionadas às ações sociais e a transformação da natureza, estas, que certamente serão sentidas nas gerações futuras. Ou seja, é necessário "sensibilizar para as enormes carências de nosso pensamento, e compreender que um pensamento mutilador conduz necessariamente a ações mutilantes" (MORIN, 2007, p. 15).

Assim, a partir de uma visão mais integral e complexa, propósitos educacionais escolares como a Educação Ambiental, tornam possível às gerações e suas ações antrópicas, a ampliação do conhecimento e da aplicabilidade de questões como a sustentabilidade. O termo sustentabilidade necessita, nessa visão, ser relacionado ao desenvolvimento tecnológico, social, econômico e produtivo, que deve ser obrigatoriamente sustentável compreendido em contexto amplo, a partir da consciência destas ações e seus resultados, quebrando com um ciclo alienado e alienante, apoiado em uma visão compartimentada e utilitarista.

Dado o exposto, o presente texto tem por objetivo inter-relacionar os temas Responsabilidade Social e Educação Ambiental, através de uma discussão das relações envoltas entre os indivíduos e desses com o meio ambiente e possibilidades de conhecimento e conscientização, tendo a Educação Ambiental como parte da Responsabilidade Social. Assim, demonstrando que as ações para a manutenção da sociedade hoje sejam tais, que possam arcar com esse desenvolvimento sem afetar as possibilidades do desenvolvimento continuado das gerações que virão.

\section{Metodologia}

O presente estudo é essencialmente baseado em pesquisa bibliográfica sobre os temas aqui inter-relacionados: Educação Ambiental e Responsabilidade Social. Para tanto, a partir da definição das temáticas, imbricações e descritores, entre eles: Meio Ambiente, Educação Ambiental, Responsabilidade Social, Sustentabilidade, no decorrer do segundo semestre do ano de 2020, se deu a seleção de leituras de estudos científicos como artigos, livros, legislação, relatórios técnicos e notícias veiculadas na mídia impressa, essas últimas, para exemplificar as ações antrópicas em relação aos temas abordados.

Revbea, São Paulo, V.16, № 5: 411-430, 2021. 
O texto utiliza-se de uma abordagem qualitativa sobre o objeto, ou seja, busca refletir sobre as questões acima delimitadas, articulando bases empíricas, conceitos e reflexões teóricas e intersubjetivas, conduzindo a interfaces e possibilidades na temática e abordagem, como contribuição de análise reflexiva. A partir das contribuições de Minayo (2001) a pesquisa qualitativa abrange a capacidade de responder a questões particulares, assim, podendo trabalhar com sentidos e significados, crenças, atitudes, valores, aspirações e motivações, adentrando nos campos dos processos, relações e fenômenos que não podem ser medidos de maneira quantificável e através de variáveis.

Educação Ambiental como exercício de Responsabilidade Social: reflexões sobre o uso dos recursos ambientais, interfaces presentes na legislação e a tarefa da educação escolar no contexto contemporâneo

A discussão envolvendo questões como o meio ambiente e a consciência da necessidade do desenvolvimento sustentável e da Educação Ambiental tem motivado grandes conferências e organizações pelo mundo, oportunidades estas, em que a discussão permanente da temática, das interfaces, alternativas e corresponsabilidades, vem se fortalecendo. Todavia, temos muito para avançar em termos de construção social e educacional escolar para com o meio ambiente, e em termos de Responsabilidade Social, tendo em vista que não basta somente ter uma legislação que oriente para o uso adequado dos recursos ambientais.

No entanto, quando se avalia as relações sociais com o meio ambiente, compreende-se que ocorrem em todas as partes, em todos os ecossistemas, utiliza-se de todos os tipos de recursos, renováveis ou não, reitera-se a importância de estabelecer contínuas e efetivas maneiras de conhecer e conscientizar sobre. Além disso, na gênese somos sujeitos extremamente dependentes uns dos outros, vivendo em sociedade e em última análise, aglomerando-se em cidades e passando a desfrutar da sociedade de consumo, estando em desacordo com a ideia de sustentabilidade. Desse modo, muitas vezes nos deparamos em um capitalismo exacerbado e inconsequente, onde a sustentabilidade que importa é aquela que permite que os sujeitos tenham todos os acessos de forma individualista, independentemente dos resultados em relação à sociedade, entendimento antagônico ao que preconizava Max Weber, ao tratar das relações sociais em interdependência.

Neste aspecto, é inerente a importante tomada de decisões e gerenciamento de políticas públicas e ações de conscientização que permitam a percepção da indissociabilidade da sociedade e da dependência do meio. Como ponto de partida, a compreensão da relação sociedade e ação social, sociedade e produção de bens materiais e bases materiais da existência, é fundamental para a emergência dos aspectos sociais, reunindo-se assim as ideias apresentadas por Durkheim, Karl Marx e Max Weber. Mas a complexidade vai para além, clarificando a amplitude e a não simplificação destas relações, imbricando também o conceito de sustentabilidade, emergindo como uma 
relação de equilíbrio entre a sociedade, suas necessidades e o meio ambiente, urgindo por processos de Educação Ambiental, atrelados a Responsabilidade Social.

A compreensão de que somos dotados de liberdade, mas responsáveis por nossas ações, presente em nossa Carta Magna, e de que estamos inseridos no meio ambiente do qual somos dependentes, denota Responsabilidade Social. Em contrapartida, um dos maiores desafios quando se coloca em pauta a questão ambiental, é o de compatibilizar o crescimento econômico com a conservação ambiental. Não obstante, esse paradigma emergente resulta no surgimento da crise ambiental, tendo como principal agente a má gestão no uso dos recursos naturais limitados ou bens finitos, voltados para satisfação das necessidades ilimitadas e infinitas do ser humano.

Assim, o conceito de Responsabilidade Social, que representa uma consciência das ações sociais e da ideia de interdependência, mas também, de responsabilização e ação voltada para a melhoria do meio, da sociedade e sua qualidade de vida, precisa ser efetivo. Neste processo, a escola como instituição histórica de construção e compartilhamento de saberes, mas acima de tudo, como instituição social, e a educação escolar como um direito de todos, precisam cumprir seu papel na formação de cidadãos conscientes, responsáveis e críticos, pautadas nas orientações legais sobre a educação e na formação superior de profissionais educadores qualificados e comprometidos socialmente. Maneia, Cuzzuol e Krohling (2013) destacam que "o cumprimento da responsabilidade social está relacionado à qualidade de ensino, à formação dos profissionais de educação, à promoção humana e dos serviços prestados".

Nesse mesmo sentido, Maneia, Cuzzuol e Krohling (2013, p. 2719) ao referirem-se as instituições educacionais de Ensino Superior destacam que,

[...] a responsabilidade social faz parte de um novo entendimento de sociedade do qual as IES não poderiam ficar ausentes. As Diretrizes da educação remetem a mudanças sociais como disseminação da cultura, a questão da ética, dentre outros, que afetam diretamente a sociedade. Por isso, é importante compreender o que nos diz Furlani: Uma das faces da responsabilidade social das instituições universitárias é a de contribuir para a eliminação das disparidades sociais e regionais existentes no País, por meio da formação de cidadãos críticos e profissionais capazes de entender as exigências da sociedade. Deve ainda responder às mudanças provocadas pelos avanços da ciência e contribuir para a construção e a disseminação dos conhecimentos. 
e que estas deparam como divisor de águas, em grande medida, com o perfil e projeto de educação pelo qual somos perpassados, seguindo currículos estruturados, hierarquizados e rígidos, moldando subjetividades e corpos. Assim, ao pensar em construir novas possibilidades na relação com o meio ambiente, precisamos entender que isso tudo não fica garantido a partir e apesar da legislação existente, uma vez que ela, enquanto discurso, precisa constantemente ser colocada em prática nas distintas interfaces sociais e na educação escolar, considerando esta como instituição social potencialmente promotora de cidadania, visão crítica e ética. Pautada na complexidade, a educação escolar precisa atuar na promoção da Responsabilidade Social, voltada para o bem comum e para a construção de novas culturas e possibilidades de ser e estar no mundo, contemplando novos perfis sociais.

Porém, em termos de legislação brasileira, assim como na reflexão acadêmica, científica e teórica, as questões voltadas para a responsabilidade Ambiental institucional e coletiva ainda são recentes, pois, somente na Constituição Federal Brasileira de 1988 (CF 1988), que se observa a presença do dever de solidariedade, representado principalmente, pelo dever de proteção ao meio ambiente, apresentado no artigo 225 onde se pode ler: "Impõe ao Poder Público e à coletividade o dever de protegê-lo e preservá-lo" (BRASIL, 2006). Se esta noção passa a ser verdade na forma da lei, no objetivo preservar para o bem comum, fortalecendo o conceito de Responsabilidade Social, cabe à educação escolar caminhar junto, promovendo a compreensão ampla da cidadania, a construção social e ética dos processos educacionais.

Nesta concepção, a Lei Federal № 12.651, de 25 de maio de 2012 (BRASIL, 2012), no seu capítulo $X$, artigo 41 define que,

é o Poder Executivo Federal autorizado a instituir, sem prejuízo do cumprimento da legislação ambiental, programa de apoio e incentivo à conservação do meio ambiente, bem como para adoção de tecnologias e boas práticas que conciliem a produtividade agropecuária e florestal, com redução dos impactos ambientais, como forma de promoção do desenvolvimento ecologicamente sustentável.

A essa afirmação, não escapa a educação escolar, principalmente pública, atuando na construção de conhecimento sobre prevenção de danos e boas práticas. Para as empresas e civis, a lei propõe ainda, que possam ser efetuados pagamentos ou incentivos a serviços ambientais, ou compensação pelo uso de medidas de conservação ambiental, que vierem a ser utilizadas como forma de cumprimento dos objetivos da Lei. Talvez esta última questão fosse menos necessária se a primeira estivesse sendo efetiva desde muito tempo, pois esta última não necessariamente conduz à conscientização. 
No mesmo sentido, a Lei № 9433/1997 que Institui a Política Nacional de Recursos Hídricos e cria o Sistema Nacional de Gerenciamento de Recursos Hídricos, promulgada em 1997 (BRASIL, 1997), no seu artigo 19, institui a cobrança pelo uso de recursos hídricos. Esta lei, embora anterior a Lei Federal № 12.651 (BRASIL, 2012) que dispõe sobre a proteção nativa, traz em sua essência a ideia de que os recursos naturais têm sim um valor econômico e, que por outro lado, não estão disponíveis a qualquer tempo para seu uso sem que esse seja planejado. Deixando claro que é um bem comum e, portanto, deve ser gerenciado de forma que possa servir a todos, proporcionando o uso múltiplo das águas, sem que haja prejuízo daquele para o uso em outras atividades. Além disso, define que o uso prioritário dos recursos hídricos é o consumo humano e a dessedentação de animais, retomando interfaces dos conceitos de sustentabilidade e Responsabilidade Social em relação aos usos múltiplos da água.

Essa mesma lei estabelece como conceito fundamental, que a gestão dos recursos hídricos deve ser descentralizada e contar com a participação do Poder Público, dos usuários e das comunidades. Logo, é de responsabilidade coletiva daqueles que interagem no espaço geográfico, bacia hidrográfica, que fazem uso do solo, dos recursos florestais e certamente dos recursos hídricos. Assim, fica claro que a ideia não é isolar parte do solo e nesse os recursos hídricos, florestais ou fauna existente para uso futuro, mas sim, traz a dimensão de que o uso deve ser com cautela e zelo, evitando a destruição ou a contaminação do solo e da água, sem ignorar que a poluição do ar está inserida nesse contexto.

Portanto, as discussões existentes em relação ao uso atual do solo, que por décadas foi realizado sem o entendimento do conceito de uso sustentável dos recursos naturais, da descentralização, da complexidade das inter-relações e funcionamento saudável dos sistemas naturais devem ser consideradas e compreendidas, inclusive e imprescindivelmente, na educação escolar. Esta deve ser uma tarefa da educação escolar voltada para as necessidades contemporâneas, uma vez que como já enfatizado, esta é sim uma construção, portanto, não é algo natural (VEIGA-NETO, 2004). Ou seja, é importante uma Educação Ambiental capaz de enfatizar novas práticas de ação antrópica, gestão, proposição para o consumo consciente e redução de desperdício da água, delineando ações emergentes para toda a sociedade, inclusive nas ações propostas para crianças pequenas em âmbito escolar (MIRANDA et al. 2021).

Além disso, deve fazer parte desses debates e atividades práticas, não somente o âmbito macro, mas o aspecto micro, porções e amostras da realidade em que vivemos, ecoando percepções e sentidos e moldando esse conceito para que se possam utilizar os recursos ambientais sem esgotá-los. Possibilidades para melhorar a condição atual, que remete a um cenário degradado por usos anteriores e que poderá afetar cada vez mais, vidas e a saúde das sociedades espalhadas pelo planeta. 
Por mais de séculos fez-se o uso do meio ambiente como se os recursos naturais fossem inesgotáveis. $\mathrm{Na}$ atual conjuntura, principalmente no meio científico, já é consenso que os recursos são finitos. E embora já existissem muitos estudos que apontavam para a necessidade de novos olhares, preconizase a urgente necessidade de políticas públicas.

Por outro lado, é importante desmistificar que determinadas áreas demandam ser isoladas e intocadas para que as gerações futuras desfrutem delas. Mas sim, é imperativo reforçar a conscientização coletiva, estimular a Responsabilidade Social e a aplicação do uso sustentável dos recursos naturais. Logo, o papel da educação se apresenta como principal ferramenta na possibilidade de formar seres humanos mais cautelosos e conscientes com o meio onde estão inseridos, pois o ensino, por seu caráter de intervenção social e potencial de preparação para novas consciências, práticas e culturas, possibilita decisivamente esse processo. Conforme segue, para Maneia, Cuzzuol e Krohling (2013, p. 2717),

[...] no Brasil atualmente, as instituições de ensino formal adotam uma prática desprovida de relevância acadêmica, voltada apenas para a interdisciplinaridade, uma maneira inadequada de se trabalhar um tema tão significativo. A questão, no entanto, é que os problemas ambientais não podem ser encarados apenas como locais ou isolados, pois o global e o local se interrelacionam. É necessário que as instituições de ensino conheçam os vários processos educacionais e organizativos e os sujeitos envolvidos para definir as linhas diretrizes norteadoras das práticas socioambientais. É importante, então, um método educativo que propicie e crie as condições para que os indivíduos tenham uma aprendizagem real que lhes permita construir os conhecimentos teóricos e práticos e axiológicos necessários para a realização de práticas ambientais conscientes e comprometidas.

É importante ter presente que a sensibilização sobre problemáticas ambientais nas práticas educacionais é necessária, que a conscientização é um processo interno, pessoal, embora não constituído solitariamente (SILVA; CRUZ, 2021). Outro ponto importante, é que embora a Educação Ambiental já esteja presente nestas, evidentemente, torna-se necessário ocorrer adaptações às leis, atenção e condições para sua efetiva aplicação. Deve-se atentar também e cada vez mais, para questões como a Responsabilidade Social em diversos setores, no intuito de estimular olhares atentos para intervir e para dar ordenamento aos usos do solo e dos recursos naturais e, para que, como consequência, se tenha qualidade de vida e a possibilidade de desfrutar da biodiversidade em tempos atuais ou, também futuros. São interligações e diálogos permanentes e necessários. 
Corroborando com os argumentos até aqui apresentados, ao situar as orientações da legislação, a relação da educação escolar, da Educação Ambiental (EA) e da Responsabilidade Social, para Maneia, Cuzzuol e Krohling (2013, p. 2717) "a EA, por conseguinte, é uma forte aliada das instituições que atuam com a educação formal no cumprimento da responsabilidade social". Assim, objetivando propiciar equilíbrio entre o homem e o seu meio, a EA se configura como instrumento para a transformação, por representar a relação entre meio ambiente e educação. No momento em que tivermos tais temáticas sendo trabalhadas de forma satisfatória ainda na formação básica, com certeza a ação social e a intervenção nos sistemas naturais serão fortalecidas em termos de aplicação da Responsabilidade Social que gera Responsabilidade Social.

Santos e Gould (2018) definem a Educação Ambiental como aquela que influencia a maneira como as pessoas entendem, pensam e conectam-se ao mundo ao seu redor. Para Uhmann e Vorpagel (2018) a Educação Ambiental é um tema transversal fundamental na sensibilização para a tomada de consciência, a fim de construir-se uma sociedade sustentável, considerando que a crise ambiental decorre principalmente dos meios e dos modos de produção.

A partir do exposto, alguns dos aspectos que serão problematizados a seguir, demonstram necessárias ações em face de resultados, em parte, ligados a uma trajetória de educação formal e escolar. Para tanto, ponderando as já citadas perspectivas de conhecimento sistematizado em estratégias curriculares fragmentárias, que muitas vezes deixam para a sociedade, cidadãos não suficientemente capacitados para desenvolver as sensibilidades necessárias com o meio ambiente em ações antrópicas, aponta-se aqui a necessidade da formação educacional que amplie a relação antrópica consciente com o meio ambiente, propiciando em última análise, a Responsabilidade Social. Ao mesmo tempo, é preciso afirmar que não se trata de questões simples e de rápida resolução, mas de algo que envolve investimentos como o de tempo, entre outros custos, para os quais é preciso ter ciência deles, resultando em consciência. Por isso, o debate precisa ser fortalecido continuamente, além de ocorrer permanente diálogo da produção acadêmica com a educação básica.

Os custos ambientais envolvidos tanto no uso como no mau uso dos recursos naturais, ampliam a justificativa da necessidade da Educação Ambiental para os cidadãos que serão futuros trabalhadores, empreendedores, agricultores, empresários do agronegócio, entre outros. Dentre estes custos, há aqueles ligados a implantação da gestão ambiental. A gestão ambiental é delineada em processos de difícil mensuração monetária, pois inexiste uma definição concreta sobre os custos ambientais. Para tanto, é necessária a definição ou avaliação de valores ou custos referentes a elementos do ambiente como: perda de solo com consequente redução na produtividade das culturas, provocado principalmente pela perda de nutrientes, erosão hídrica, perda da cobertura florestal, perda de espécies florestais, redução na fauna, entre outros. Feito isso, espera-se que o planejamento consciente seja realizado na premissa de ações futuras que reflitam boas condutas junto ao meio ambiente. 
Colaborando com essa definição Ribeiro, Gonçalves e Lima (2002) afirmam que custos ambientais são os consumos de recursos ocorridos na área de produção, mas voltados especificamente ao controle e conservação ambiental, tais como todos os insumos inseridos no processo operacional que tenham por objetivo a eliminação ou redução dos poluentes. Por outro lado, Sá (2002) alerta que de nada adianta que os custos ambientais estejam presentes nos demonstrativos contábeis se não houver uma conscientização da necessidade do cuidado com o meio ambiente.

Em referência a observação destes aspectos em âmbito local, tais efeitos foram evidenciados na região norte do estado do Rio Grande do Sul, entre outros momentos, no mês de maio de 2011, quando uma esterqueira usada como reservatório para dejetos provenientes da criação de suínos estourou em razão de intensas chuvas no período e, consequentemente, os dejetos alcançaram as águas do Lajeado Pardo. Como resultado imediato, teve-se o corte do abastecimento da água para a população dos municípios de Frederico Westphalen e Caiçara, no RS, durante dois dias seguidos. Esse caso foi noticiado na imprensa local, especificamente no Jornal O Alto Uruguai, edição do dia 18 de maio de 2011, sob a manchete "Crime ambiental deixa municípios sem água".

Outro exemplo que pode ser citado, porém, este de repercussão internacional, é o rompimento da Barragem do Fundão em Brumadinho - MG, em janeiro de 2019. Na região da barragem, segundo o relatório do Conselho Nacional dos Direitos Humanos $(\mathrm{CNDH}, 2019)$, o resultado do rompimento deixou 24 mil pessoas em áreas de risco, além do fato de que esse acidente ocasionou 233 óbitos (G1 MINAS, 2019). Ainda, no mesmo relatório, foram citados os impactos ambientais constatados no rompimento da barragem do Fundão (CNDH, 2019),

os parâmetros turbidez, cor verdadeira, ferro dissolvido, manganês total, alumínio dissolvido, mercúrio total e chumbo total para avaliar a evolução temporal dos dados dos parâmetros tem apresentado violações aos limites de classe 2 na Deliberação Normativa Conjunta COPAM/CERH-MG n 01/2008 e da Resolução CONAMA no 357/2005.

A relevância de citar esses casos deve-se ao fato de que independentemente do tamanho do impacto ambiental causado por esses eventos, fica evidente que o custo ambiental, mesmo em função dos esforços que sejam feitos para serem mensurados, não podem efetivamente estabelecer um valor monetário para esses acidentes, pois, em muitos casos, o direito à vida foi comprometido. Dessa maneira, novamente o conceito de Responsabilidade Social foi ferido, pois os atos destas empresas e pessoas resultaram em consequência para toda a sociedade, e o conceito de sustentabilidade foi irreversivelmente fragmentado, especialmente no caso de Brumadinho - MG,

revista brasileira educação ambiental 
considerando que gerações foram comprometidas em razão da perda da biodiversidade, de vidas humanas, de histórias e memórias das famílias e comunidades. Segundo o CNDH (2019) não se trata de "mero evento, constituindo-se em verdadeiro desastre tecnológico e criminoso".

No entanto, além desses exemplos que são acontecimentos envolvendo impactos ambientais de grandes proporções, é cabível ainda tratar como custos ambientais os provocados pela erosão hídrica, oriundos das atividades antrópicas cotidianas no meio rural, fruto da exploração agrícola, que são um dos principais problemas relacionados ao manejo dos solos no país. E segundo Silva et al. (2005), tem contribuído para o empobrecimento, redução e/ou perda de sustentabilidade dos agro ecossistemas, decorrentes do arraste de solo, nutrientes e carbono orgânico a ela associada. Assim, pode-se perceber que os resultados desse processo atuam na perda de solo.

É fato que as ações antrópicas causadoras da erosão dos solos são um problema ambiental e social, e vários esforços têm sido realizados para mensurar as perdas causadas pela erosão. Para tanto, pode-se destacar os estudos realizados pela Organização das Nações Unidas para Alimentação e Agricultura (FAO, 2013) onde é relatado que mais de $33 \%$ dos solos no mundo estão degradados, afetando suas funções e colocando em risco a segurança alimentar. $\mathrm{O}$ estudo ainda aponta os processos erosivos como responsáveis por eliminarem de 25 a 40 bilhões de toneladas de solo por ano. Afirmação essa corroborada por Dechen et al. (2015), que com base em resultados de experimentos, afirmam que os custos da erosão do solo relacionados às perdas de nutrientes como fósforo, potássio, cálcio, magnésio, em lavouras anuais no Brasil, são da ordem de US\$ 1,3 bilhão ao ano. Certamente estas perdas interferem e contribuem para o aumento dos custos de produção em função do aumento da necessidade do uso de corretivos do solo e fertilizantes, além de reduzir o rendimento operacional das máquinas agrícolas (SILVA, et al. 2005).

Perante as definições acima mencionadas, fica evidenciado que não há um atendimento ao preceito de que existe um custo ambiental nas atividades de produção, no meio urbano e rural. Assim sendo, a não atenção a essa sistemática de custos, acarreta impactos ambientais ou acidentes ambientais de grandes proporções, chegando ainda a se tornarem desastres ambientais. Tudo isso, remete para a perspectiva da urgência da Educação Ambiental e da Responsabilidade Social.

Nesse sentido, todos os aspectos abordados anteriormente, devem fazer parte de um processo de implementação de medidas, entre elas, a Educação Ambiental, principalmente quando entendido que o direito ao meio ambiente foi incluído na Constituição Federal de forma explícita no Art. 225 (BRASIL, 2006), 
todos têm direito ao meio ambiente ecologicamente equilibrado, bem de uso comum do povo e essencial à sadia qualidade de vida, impondo-se ao Poder Público e à coletividade o dever de defendê-lo e preservá-lo para as presentes e futuras gerações.

É urgente que os aspectos ora abordados, transcendam a academia e passem a fazer parte da educação escolar e demais fases da educação formal e do cotidiano da população. Isso fica ainda mais evidente quando se lê no $\S 1^{\circ}$ do Art. 225 da Constituição Federal, no parágrafo VI que ao poder público compete: "promover a Educação Ambiental em todos os níveis de ensino e a conscientização pública para a preservação do meio ambiente".

Para Aguiar et al. (2017, p. 113),

a EA, diante de um contexto internacional de degradação ambiental em escala alarmante, é uma necessidade urgente de ser efetivada no processo educacional formal, mas também em outros âmbitos da sociedade. Documentos e legislações intergovernamentais, na esfera internacional, e documentos e legislações governamental na esfera nacional brasileira, já vêm apontando de longa data essa importância da EA voltada para a mudança de pensamento e de atitudes por parte da sociedade a partir de uma conscientização sobre a importância da conservação ambiental.

Não se trata aqui apenas de aplicar a lei, mas, também, de conscientizar as pessoas através de um processo gradual, mas efetivo, de construção interdisciplinar de conhecimentos que este campo de estudos exige, e na crítica à fragmentação do conhecimento (SAUVÉ, 2005) na compreensão da complexidade, e do imbricamento da ação humana, mostrando os impactos e as possíveis mudanças de atitudes e inserção efetiva de ideias sustentáveis, quebrando com a dicotomização da relação entre natureza e sociedade. Conforme Morin (1999b), "complexus é o que é tecido em conjunto; é o tecido obtido a partir de fios diferentes e que se transformaram num só". Por outras palavras, tudo isso se cruza e volta a cruzar, se tece e volta a tecer, para formar a unidade da complexidade; mas a unidade do complexus não destrói a variedade nem a diversidade das complexidades que a teceram.

Importante citar que a Lei no 9.795/99 de 27 de abril de 1999 cria as diretrizes para a Educação Ambiental e institui a Política Nacional de Educação Ambiental. A EA pode ser entendida segundo Brasil (1999) como, 
processos por meio dos quais o indivíduo e a coletividade constroem valores sociais, conhecimentos, habilidades, atitudes e competências voltadas para a conservação do meio ambiente, bem de uso comum do povo, essencial à sadia qualidade de vida e sua sustentabilidade.

Novamente, nessa teia construtiva do conhecimento esbarra-se no termo sustentabilidade e questões sociais e coletivas, que de forma inequívoca nos levam de volta aos pensadores anteriormente citados, que se preocupavam com essa relação, embora não se utilizassem destes mesmos conceitos e dimensões. Além disso, o desenvolvimento econômico, social, ético, político e cultural deve ser tal, não por acaso, mas pensado para ser assim, onde possibilite a continuação das gerações que virão, mantendo-se as relações entre os indivíduos e desses com a sociedade por eles formada, abrangendo as organizações com o meio ambiente que recebe e sustenta a vida através dos recursos naturais que, frequentemente, são acometidos.

Nessa ótica, embora muito se tenha desenvolvido no campo de estudos da Educação Ambiental na relação com a educação escolar e a Responsabilidade Social a partir da CF 1988 e outras normatizações já citadas, ainda é preciso fortalecer a relação dos estudos com a formação docente e continuada, com a prática pedagógica docente e a construção de currículos e Projetos Político-Pedagógicos escolares.

A partir da CF 1988, várias ações com propósitos já supracitados foram olhadas com embasamentos como da Lei Federal no 9.795, de 27 de abril de 1999, que instituiu a Política Nacional de Educação Ambiental, Programa Nacional de Educação Ambiental (PRONEA), bem como: em 1997 os Parâmetros Curriculares Nacionais (PCNs), quando um novo impulso foi dado à Educação Ambiental no Brasil, mais especificamente no ensino escolar. Embora alguns estudiosos questionem o fato de que a Educação Ambiental não tenha se tornado uma disciplina, os PCNs justificam esse fato apontando que a Educação Ambiental será mais bem trabalhada como um tema transversal, estando no âmbito de todas as disciplinas, o que permitirá seu enfoque de forma mais global e interdisciplinar (BRASIL, 1997), possibilitando a construção da cidadania - conforme preconizada pela Lei de Diretrizes e Bases da Educação Nacional (Lei no 9.394, de 20 de dezembro de 1996). Os PCNs de número nove são dedicados especificamente ao tema "Meio Ambiente e Saúde" (AGUIAR et al. 2017, p. 124).

Também merecem destaque as Diretrizes Curriculares Nacionais (DCNs) para a Educação Ambiental, por meio da Resolução CNE/MEC no 02 de 15/06/2012. Este documento está atrelado a uma perspectiva que em alguma medida situa- se mais aproximada ao pensamento complexo de Morin, com caráter interdisciplinar e de temáticas transversais na Educação Ambiental, conforme afirma em seu Art. $8^{\circ}$ : de que "A Educação Ambiental, respeitando a autonomia da dinâmica escolar e acadêmica, deve ser desenvolvida como uma 
prática educativa integrada e interdisciplinar, contínua e permanente em todas as fases, etapas, níveis e modalidades".

Entretanto, atualmente, acompanhando uma onda de retrocessos e posturas mais alinhadas a certo conservadorismo, os últimos documentos norteadores das práticas e currículos escolares como a Base Nacional Comum Curricular - BNCC, aprovada em dezembro de 2017, portanto já em implementação nas escolas do país, não tem sido visto como avanços significativos neste sentido. Conforme Behrend, Cousin e Galiazzi (2018 p. 8283) "as questões ambientais estão sendo tratadas na BNCC de forma reduzida, restringindo-se, basicamente, nas disciplinas de Ciências da Natureza e Geografia", afirma que "a inserção da Educação Ambiental não é significativa e se mantém ausente em diversas disciplinas", demonstrando assim, que a "corrente conservacionista se faz presente nas unidades de significado analisadas". Assim, tratada de forma fragmentada e não garantindo o alcance necessário e devido, frente a uma temática tão significativa.

Inequivocamente a educação escolar aliada à Educação Ambiental e a compreensão que engloba a perspectiva do conceito de Responsabilidade Social, se entrelaçam em um perfil de educação que, de imediato, parte de uma efetiva ruptura epistemológica com um tipo de conhecimento, por vezes, voltado exclusivamente para o aspecto técnico-científico colocado a serviço dos interesses da expansão capitalista a qualquer custo. No entanto, corroborando com o que fica claro no decorrer deste texto, Morin (1999b) ressalta que este trabalho de reforma do pensamento deveria se iniciar ainda na escola primária, não desconsiderando a importância dele no meio universitário, mas, para o autor, é nesse nível que se deve beneficiar da maneira natural e espontaneamente complexa do espírito da criança, para desenvolver o sentido das relações entre os problemas e os dados.

Isso implica em reconhecer a cultura e sua construção como algo decisivo para com a sociedade, como lente para o agir humano, como construção social, um continuum que ocorre nas relações sociais humanas e na produção e construção das vivências e experiências, inclusive escolares. Rüsen (2014) afirma que a cultura dá ao ser humano a possibilidade de atribuição de sentido para agir no mundo e para a forma como ele age. Então, tais processos resultam de diferentes sentidos que são colocados na práxis humana, na ação racional humana, em relação à natureza. Pois,

a cultura é a resposta que os seres humanos atuantes e sofredores dão a si próprios ao lidarem com a natureza, com o seu próprio mundo social e consigo mesmos e com os outros seres humanos, quando perguntam pelo sentido de sua vida e querem organizá-la de um modo que faça sentido. O sentido determina como as experiências são feitas, como o que se experimenta é interpretado e como as interpretações são empregadas para orientar a práxis vital e motivar à vontade. A cultura se manifesta no cosmo dos símbolos que transformam a natureza em mundo humano (RÜSEN, 2014).

Revbea, São Paulo, V.16, № 5: 411-430, 2021.

revista brasileira

educação ambiental 
Com diferentes bagagens culturais, compreendemos, reagimos e agimos de diferentes formas nas relações a partir da atribuição de sentidos, estranhamentos e confrontos, diálogo e hibridização. Para Bauman (2012), a cultura só pode existir como crítica prática e intelectual da realidade social existente, como práxis. Esta crítica é capaz de produzir novos olhares e atitudes, e, assim, as ações sociais não são pautadas em definições estáticas.

Nesse sentido, é de suma importância produzir novas perspectivas culturais, entender as relações interdependentes e complexas, e pensar neste escopo. Compreender que as relações sociais e com o meio, geram em nosso modelo econômico, tanto pelo mau uso, quanto pela sua conservação, um custo ambiental. Consequentemente, só pode ser realmente entendido, desmistificado e difundido se houver aplicação da Responsabilidade Social na educação escolar e na Educação Ambiental emancipatória e cidadã dos sujeitos a partir de princípios dialógicos que coloquem no debate interfaces e aspectos éticos, culturais, filosóficos, técnicos, espirituais, científicos, históricos e sociológicos em um imbricamento contínuo, que possa resultar em conhecimento e reconhecimento e, assim, em ampliação e continuidade da Responsabilidade Social consciente. É nessa ótica que conceitos como o de sustentabilidade serão aplicáveis e terão seus efeitos sentidos ao longo das gerações.

\section{Conclusões}

Os aspectos aqui elencados reforçam o entendimento de que a Educação Ambiental é um tema transversal (UHMANN, VORPAGEL, 2018) e interdisciplinar, e que para atingir a sustentabilidade entre as relações antrópicas e o meio ambiente existe a necessidade da conscientização de que para o entendimento dessa relação, necessariamente, temos de conhecer os conceitos com sua aplicação holística, integral, e a sociedade em sua complexidade, pautando-se em Responsabilidade Social.

Pelos exemplos expostos, ratifica-se mais uma vez, que a não compreensão e o não atendimento ao preceito de que existe um custo ambiental nas atividades de produção, pode resultar em impactos ambientais ou acidentes ambientais. Contudo, a sua remediação sempre será de um custo ambiental maior que a construção cultural e a aplicação dos conceitos fundamentais que envolvem a Educação Ambiental e a aplicação da Responsabilidade Social pelas pessoas e instituições. E que durante o planejamento, a execução e o controle das atividades antrópicas de produção e transformação no meio ambiente, as perspectivas de ação não são dadas como receitas prontas, mas, como reorganizações estratégicas e processuais, conforme Morin (1999b), na arte de utilizar as informações que surgem durante a ação, integrá-las, formular subitamente esquemas de ação e ser capaz de reunir o máximo de certezas para defrontar o incerto, em processos de gestão.

Fica claro ainda, que se de um lado tem-se o regramento jurídico 
empresas e gestores, do outro, deve haver o entendimento de que o uso dos recursos naturais deve ser consciente. Dessa maneira, é impreterível incorporar as noções de consciência ambiental, Educação Ambiental e sustentabilidade para a produção de matéria prima, bens e serviços, que permitam e que não inviabilizem a continuidade da vida no planeta Terra.

Apesar da educação escolar não ter o objetivo de preparar tecnicamente a sociedade para questões mais pontuais relacionadas à gestão ambiental e demais aplicações, questões estas reservadas a cursos superiores e técnicos, entende-se que, desde que haja consciência e Responsabilidade Social, preparo ético e crítico, conhecimento amplo do ambiente e complexo das interrelações, as ações antrópicas poderão ser mais responsáveis. Ainda, a interpretação e aplicação da lei podem ser facilitadas e não vistas à revelia, e a contratação de técnicos para auxiliar no processo pode ser vista como ganho e não como algo que viria em desproveito da produção e da rentabilidade das empresas e propriedades e dos meios coletivos de vivência. Assim, a consciência da complexidade é o caminho para construir soluções mais adequadas para aquilo que nos é tão caro: a garantia de um ambiente e uma vida mais saudável.

\section{Referências}

AGUIAR, P. C. B DE. et al. Da Teoria à Prática em Educação Ambiental. Revista Gestão \& Sustentabilidade Ambiental, v. 6, n. 2, 2017.

ALMEIDA, K, K, N.; BATISTA, F, F. Provisões Contingentes Ambientais e seus Reflexos no Endividamento das Empresas de Alto Impacto Ambiental Após Adoção do CPC 25. Sociedade, Contabilidade e Gestão, v. 11, n. 1, 2016.

ARAÚJO, G. F. Estratégias de Sustentabilidade: aspectos científicos, sociais e legais: contexto global: visão comparativa. $1^{\underline{a}}$ ed. São Paulo- SP: Editora Letras Jurídicas, 2008,128p.

BAUMAN, Z. Cultura como práxis. In: Ensaios sobre o conceito de cultura. Rio de Janeiro- RJ: Zahar, 2012, 328p.

BEHREND, D. M.; COUSIN, C. da S.; GALIAZZI, M. do C. Base Nacional Comum Curricular: $O$ que se mostra de referência à Educação Ambiental? Ambiente e Educação: Revista de Educação Ambiental, v. 23, n. 2, 2018.

BRASIL. Constituição da República Federativa do Brasil de 1988, de 5 de outubro de 1988. Brasília - DF, 1988. Disponível em:< http://www.planalto.gov.br/ccivil 03/constituicao/constituicao.htm>. Acesso em: 09 jul. 2021.

BRASIL. Lei № 12.651, de 25 de maio de 2012. Dispõe sobre a proteção da vegetação nativa. Disponível em: $<$ http://www.planalto.gov.br/ccivil 03/ ato2011-2014/2012/lei/12651.htm>. Acesso em: 09 jul. 2021. 
BRASIL. Lei № 9433, de 08 de janeiro de 1997. Institui a Política Nacional de Recursos Hídricos, cria o Sistema Nacional de Gerenciamento de Recursos Hídricos. Disponível em: < http://www.planalto.gov.br/ccivil 03/leis/19433.htm>. Acesso em: 09 jul. 2021.

BRASIL. Lei № 9.795, de 27 de abril de 1999. Dispõe sobre a Educação Ambiental, institui a Política Nacional de Educação Ambiental e dá outras providências. Disponível em: http://www.planalto.gov.br/ccivil 03/leis//9795.htm>. Acesso em: 09 jul. 2021.

CASSOL, E. A.; LIMA, V. S. Erosão em entressulcos sob diferentes tipos de preparo e manejo do solo. Pesquisa Agropecuária Brasileira, v. 38, n. 1, 2003.

CHAKRAVORTI, B. How companies can champion sustainable development. Harvard Business Review, 2017. Disponível em: < https://hbr.org/2017/03/howcompanies-can-champion-sustainable-development>. Acessado em: 09 jul. 2021.

CMMAD - Comissão Mundial sobre o Meio Ambiente e Desenvolvimento. Nosso Futuro Comum. $2^{\underline{a}}$ ed. Rio de Janeiro- RJ: Editora Fundação Getúlio Vargas, 2011. Disponível em: https://edisciplinas.usp.br/pluginfile.php/4245128/mod resource/content/3/Noss 0\%20Futuro\%20Comum.pdf>. Acesso em: 09 jul. 2021.

$\mathrm{CNDH}$ - Conselho Nacional dos Direitos Humanos. Relatório da missão emergencial a Brumadinho/MG após rompimento da Barragem da Vale S/A-Brasília, 2019. Disponível em: < https://www.gov.br/mdh/ptbr/assuntos/noticias/2019/fevereiro/missao-emergencial-do-cndh-apresentarelatorio-sobre-rompimento-de-barragem-davale/RelatrioMissoemergencialaBrumadinho.pdf>. Acesso em: 09 jul. 2021.

COLUNA Meio Ambiente: Crime ambiental deixa municípios sem água. Jornal O Alto Uruguai. Frederico Westphalen. Edição de 18 de maio de 2011, p, 04, 2011.

DECHEN D. et al. Perdas e custos associados à erosão hídrica em função de taxas de cobertura do solo. Bragantia, v. 74, n. 74, 2015.

DURKHEIM, É. Lições de Sociologia - a Moral, o Direito e o Estado. São Paulo- SP: Editora da Universidade de São Paulo, 2ª edição,1969, 400p.

FAO - Food and Agriculture Organization of the United Nations. 2013. Plan de Implementación Regional (PIR) de los Pilares de Acción de la Alianza Mundial por el Suelo (AMS) para los países de América del SUR. Disponível em: < http://www.fao.org/3/bl106e/bl106e.pdf>. Acesso em: 09 jul. 2021.

G1 Minas. Brumadinho: chega a 233 número de mortos identificados em rompimento de barragem da Vale. GLOBO.COM. Disponível em: https://g1.globo.com/mg/minas-gerais/noticia/2019/04/24/brumadinho-chega-a233-numero-de-mortos-identificados-em-rompimento-de-barragem-davale.ghtml. Acessado em: 9 abr. 2020. 
HOLLIDAY, O. J. Para sistematizar experiências; tradução de: Maria Viviana V. Revista. Brasília: MMA, 2006. Disponível em: <http://revistas.abaagroecologia.org.br/index.php/cad/article/download/22322/12781/>. Acesso em:21 abr. 2021.

MANÉIA, A.; CUZZUOL, V.; KROHLING, A. A Educação Ambiental e a responsabilidade socioambiental nas práticas ambientais em instituições de ensino superior no Brasil. Revista Eletrônica em Gestão, Educação e Tecnologia Ambiental, v. 13, n. 13, 2013.

MINAYO, M. C. de S. et al. Pesquisa Social. Teoria, método e criatividade. $21^{\text {a }}$ ed. Petrópolis- RJ: Vozes, 2002. 80p.

MARX, K. Lire Le capital. Lachâtre, 1875. 894p.

MIRANDA, D. L. et al. Educação Ambiental a partir da Agenda 2030: experiências da conscientização e do uso racional da água em uma escola municipal de Varginha (MG). Revista Brasileira de Educação Ambiental, v.16, n. 2, 2021.

MORIN, E. Ciência com consciência. Rio de Janeiro: Bertrand Brasil, 1999a. 350p.

MORIN, E. Por uma Reforma do Pensamento. In: PENA-VEGA (org.). O pensar complexo. Rio de Janeiro: Garamond, 1999b.

MORIN, E. Introdução ao pensamento complexo. Porto Alegre- RS: Sulina, 2007. 120p.

PRUSKI, F. F. Conservação de solo e água: práticas no controle da erosão hídrica. $2^{\mathrm{a}}$ Ed. Viçosa- MG: Editora UFV, 2013. 279p.

RIBEIRO, M. de S.; GONÇALVES LIMA, R. C. M. Aspectos de Contabilização do Passivo e Ativo Ambientais nas Termelétricas Brasileiras. Revista de Contabilidade, v. 6, n. 20, 2002.

RIBEIRO, M. de S. GRATÃO, A. D. Custos ambientais - o caso das empresas distribuidoras de combustíveis. In CONGRESSO BRASILEIRO DE CUSTOS, 7, 2000, Recife. Anais Eletrônicos do VII Congresso Brasileiro de Custos, RecifePE, 2000.

RIBEIRO, M. de S. Contabilidade ambiental. Editora Saraiva, 2017. 360p.

RÜSEN, J. Cultura Faz Sentido: orientações entre o ontem e o amanhã. Petrópolis- RJ: Editora Vozes, 2014. 368p.

SÁ, A. L. Progresso no Campo da Contabilidade Aplicada aos Fatos do Ambiente Natural. Revista Pensar Contábil, v. 5, n. 17, 2002.

SANTOS, N, B.; GOULD, R, K. Can relational values be developed and changed? Investigating relational values in the environmental education literature. Current Opinion in Environmental Sustainability, v. 35, 2018. 
SAUVÉ, L. Uma cartografia das correntes em Educação Ambiental. In: SATO, M.; CARVALHO, I. Educação Ambiental: pesquisa e desafios. Guarulhos- SP: Artmed Editora, 2005.

SILVA, A. M. et al. Perdas de solo, água, nutrientes e carbono orgânico em Cambissolo e Latossolo sob chuva natural. Pesquisa Agropecuária Brasileira, v. 40, n. 12, 2005.

SILVA, P. S. A. da.; CRUZ, L. de J. S. Problematização concepções de professores de ciências sobre Educação Ambiental e cidadania crítica: uma parceria entre o engenheiro ambiental e a escola. Revista Brasileira de Educação Ambiental, v. 16, n. 2, 2021.

UHMANN, R. I. M.; VORPAGEL, F. S. Educação Ambiental em Foco no Ensino Básico. Pesquisa em Educação Ambiental, v. 13, n. 2, 2018.

VEIGA-NETO, A. Algumas raízes da Pedagogia moderna. In: POLENZ, T. (org.) Pedagogia em conexão. Canoas, 1를 ed. Editora ULBRA, 2004.

WEBER, M. The theory of social and economic organization. Free Press, New York- USA, 1964. 450p 